\title{
Covid-19 Demographics from a Tertiary Care Center: Does It Depreciate Quality-of-Life?
}

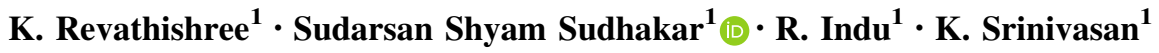

Received: 28 July 2020/Accepted: 7 September 2020/Published online: 15 September 2020

(C) Association of Otolaryngologists of India 2020

\begin{abstract}
Novel Coronavirus-disease-2019 (Covid-19) caused by the severe-acute-respiratory-syndrome coronavirus-2 (SARS-CoV-2) shows a rapid spread all over the world. It's still an ongoing pandemic with greater morbidity and mortality. In our study, we describe clinical features, and demographics of patients presenting to our tertiary care center with Covid-19 infection. Global burden was around 14 million Covid-19 positive cases with .5 million deaths and rising as per WHO update. A descriptive analytical cross-sectional study was carried out from June 1 st to 30th, 2020 in a tertiary care center. Patients who tested positive by Reverse Transcriptase-Polymerase chain reaction were included in the study and clinical characteristics and outcome of the patients were analyzed along with impact on quality-of-life. Sample size was 250 . Mean age was around 41 years, with age range from 15 to 75 years. Gender ratio was 1:2.4, with male preponderance. Most common presenting symptom was throat pain (60\%). Rhinorrhea and sneezing complaints were not recorded. Clinical categorization was done and scored accordingly. Clinical outcomes of above patients showed complication rate $5.2 \%$, mortality rate $.8 \%$, with discharge and recovery rate being rate $94.8 \%$ and $96 \%$ respectively. Fear of COVID-19 scale was used to assess quality-of-life impact. We found throat pain was the most common symptom in our study. No cases reported with rhinorrhea/sneezing. Good recovery rate noted. Quality-of-life impacted.
\end{abstract}

Sudarsan Shyam Sudhakar

b7shyam@yahoo.com

1 Department of ENT-HNS, Saveetha Medical College and Hospital, No. 1, Saveetha Nagar, Thandalam, Chennai, Tamil Nadu 602105, India
Keywords Covid-19 - SARS-CoV-2 .

DEMOGRAPHICS · Outcomes · Quality-of-life ·

RT-PCR · Fear of COVID-19 scale

\section{Introduction}

The ongoing pandemic of coronavirus disease 2019(Covid19) [1], caused by severe-acute-respiratory-syndrome coronavirus-2 (SARS-CoV-2), has infected nearly 14 million patients worldwide, with over .5 million deaths [2]. According to the World Health Organization (WHO), more than 167 countries/territories had confirmed cases (WHO, 2020) [3]. As of July 2020, more than 1 million patients have been diagnosed with covid-19 in India, the 3rd most affected country worldwide [3]. Its associated with rapid transmission rate and relatively high mortality [4-6]. Though the pandemic is starting to tip off as a plateau, new case spikes seem to be reported from clusters across the state. In local areas, discrimination of patients affected by covid-19, stress, fear/anxiety of covid-19 spread has been sporadically reported. This came in wake of initiatives by the government machinery to spread awareness on covid19 with droplet-transmission being determined as the primary route of spread $[7,8]$. This situation could possibly expose any pre-existing/sub-clinical mental disorders due to fear of the disease and become a social issue as mental health research is evolving in current emergent situation [9-12].

Most of the studies were published by China, United States, Europe. We describe demographics and clinical outcomes of covid-19 disease in India at our tertiary care center. Total number of covid-19 cases in Tamilnadu165,714 , recorded cases-113,656, active cases-49,455, deceased-2403 as of study date and ranked 2 nd affected 
state in India [13]. With varied symptomatology, some misconceptions and stigmatization have arisen. Hence, our study researched covid-19 demographics, clinical presentation, and quality-of-life changes the patients underwent during their course of admission and afterwards.

\section{Aim of the Study}

To clinically categorize covid-19 positive patients from a demographic point of view. Study it's impact on quality-oflife.

\section{Materials and Methods}

A prospective descriptive-analytical cross-sectional study was carried out in 250 Covid-19 positive patients from June 1st-30th, 2020 at a tertiary care center at Thandalam, Chennai, Tamil Nadu, India. This study was approved by the institutional ethical committee. Our center was enlisted in Government's panel for covid-19 pandemic management with rapid response covering population from Chennai, Kanchipuram, Chengalpattu, Tiruvallur districts which are in and around our center. The sample size included all hospital beds allotted for covid-19 patients $(\mathrm{n}=250)$ which included 230 ward beds and 20 ICU beds (10 with ventilator and 10 without). All consecutive samples were included in the study by convenient sampling technique. All patients who were admitted provided written informed consent. Danger-in-list, tracheostomy, intubation, ventilator-consents were also obtained depending on the category of admission and those who worsened symptomatically. Patients below 18 years of age, written informed consent was given by guardian. Demographic details recorded. Categorization of patients was done at initial admission/presentation to emergency department (Table 1). Each category was tagged with a score based on the first 5 parameters-A (score of 3 each), B (score of 2 each) and $\mathrm{C}$ (score of 1 each). 6th Parameter (Co-morbid) was noted as either + ve (value 1) or -ve (value 0 ) giving a maximum of 16 and a minimum of 6 . This was done in an effort to objectively assess the clinical status. The higher the value, the better was the clinical scenario. Treatment outcome was documented twice daily for isolation wards and thrice daily for ICUs. Investigations for each category were per protocol (Table 2).

Nasopharyngeal and oropharyngeal swabs were collected using covid-19 kiosk and samples were sent to King's institute, Guindy, Chennai. Contact-traces of the individual was collected with available Aadhar ID numbers and submitted to the Tamil Nadu Government as per the Indian Council of Medical Research (ICMR) guidelines [14]. All the patients were admitted in different isolation wards according to their category. Treatment regimen was directed by hospital protocol (Table 3). Patients who were Category $\mathrm{C}$ at the time of admission and other patients who worsen to Category $\mathrm{C}$ were shifted to respiratory intensive care unit (RICU) for further management. Symptoms at the time of admission and clinical outcomes were followed up for the next 15 days. Patients with pre-existing co-morbidities were treated accordingly. Patients who were taken up for emergency surgical procedures at the time of admission were shifted to isolation wards post operatively. Hydroxychloroquine (HCQ) was not included in the regimen.

Covid-19 testing for newborn was not done unless warranted. As per hospital protocol, tracheostomy was done for covid-19 positive intubated patients if number of days on ventilator exceeded 10 days. Patients who required dialysis were shifted to covid-19 dialysis units. All operative procedures were done in theatres with laminar flow, HEPA filters and positive pressure ventilation. Full personnel protection equipments (PPEs), proper donning and doffing with adequate sanitization and published Government protocols were adhered to.

\section{Inclusion Criteria}

1. Covid-19 positivity by RT-PCR.

2. Age between 15 and 75 years.

3. Direct referral/no treatment elsewhere.

Table 1 Clinical categorization

\begin{tabular}{lllll}
\hline Sr. no. & Criteria & Category A & Category B & Category C \\
\hline 1 & Pulse/min & $60-100$ & $100-120$ & $>120$ \\
2 & Systolic blood pressure & $>120$ & $100-120$ & $<100$ \\
3 & Diastolic blood pressure & $>80$ & $70-80$ & $<70$ \\
4 & $\mathrm{SpO}_{2}$ & $>95 \%$ without $\mathrm{O}_{2}$ & $>95 \%$ with O2 & $<95 \%$ with $\mathrm{O}_{2}$ \\
5 & Respiratory rate/min & $<18$ & $18-24$ & +24 \\
6 & Co-morbid & \pm & + & + \\
\hline
\end{tabular}


Table 2 Category specific investigation panel

\begin{tabular}{|c|c|c|c|}
\hline Sr. no. & Category A & Category B & Category $\mathrm{C}$ \\
\hline 1 & Complete blood count & Category A + & Category $\mathrm{B}+$ \\
\hline 2 & Erythrocyte sedimentation rate & Arterial blood gas analysis & Serum IL-6 \\
\hline 3 & Random blood sugar & D-dimer & \\
\hline 4 & HBA1C & Serum ferritin & \\
\hline 5 & Renal Function Test & CT thorax & \\
\hline 6 & Liver Function Test & & \\
\hline 7 & Urine routine & & \\
\hline 8 & Chest X-ray & & \\
\hline 9 & ECG & & \\
\hline 10 & C-reactive protein & & \\
\hline
\end{tabular}

Table 3 Category-wise treatment protocol

\begin{tabular}{|c|c|c|c|}
\hline $\begin{array}{l}\text { Sr. } \\
\text { no. }\end{array}$ & Category A & Category B & Category $\mathrm{C}$ \\
\hline 1 & $\begin{array}{l}\text { T. Azithromycin } 500 \mathrm{mg} \text { OD } \\
5 \text { days }\end{array}$ & Category A + & Category B + \\
\hline 2 & $\begin{array}{l}\text { T. Vitamin C } 500 \mathrm{mg} \text { OD } \\
10 \text { days }\end{array}$ & $\begin{array}{l}\text { Inj. Enoxaparin } 40 \mathrm{mg} \text { SC BD (if D-Dimer } \\
\text { elevated) }\end{array}$ & Inj. Cefaperazone + Sulbactam 1.5gm IV BD \\
\hline 3 & T. Zinc $50 \mathrm{mg}$ OD 10 days & $\begin{array}{l}\text { T. Favipiravir } 1600 \text { BD day } 1,800 \mathrm{mg} \mathrm{BD} \\
\text { days2-13 }\end{array}$ & Inj. Methyl Prednisolone 125 mg IV OD \\
\hline 4 & T. Paracetamol $650 \mathrm{mg}$ SOS & & Inj. Tocilizumab 8 mg/Kg (if IL6 elevated) \\
\hline 5 & $\begin{array}{l}\text { T. Vitamin-D3 } 1000 \text { IU OD } \\
10 \text { days }\end{array}$ & & $\begin{array}{l}\text { Inj. Remdesivir } 200 \mathrm{mg} \text { IV on day } 1,100 \mathrm{mg} \text { IV from } \\
\text { day } 2-10\end{array}$ \\
\hline
\end{tabular}

\section{Exclusion criteria}

1. Newborn babies of covid-19 positive mothers

2. Patients who refused admission and requested referral to other nodal centers

3. Patients in NICU (Neonatal) and PICU (Pediatric)

Data were collected and tabulated in Microsoft Excel. Continuous and categorical data were represented as mean \pm standard deviation and percentage respectively. Fear of Covid-19 scale (FCV-19S) [15, Appendix A] was used to assess impact of the disease on quality-of-life for the study population. Correlation of patient's objective category score with fear of covid-19 scale was done to check for any statistical significance. IBM SPSS v25 [IBM Corp. Released 2017. IBM SPSS Statistics for Windows, Version 25.0. Armonk, NY: IBM Corp.] was used for statistical analyses. FCV-19S scale was filled once during admission and next during review 10 days after discharge. Both documents were distributed and collected by the ENT department Junior Resident who was blinded. The resident provided with vernacular support if required-All respondents fully understood the item descriptions. In case of status deterioration/death, higher values were proxy-/autoassigned. All patients underwent psychological counseling before discharge and once during review. All review patients were dealt in a separate OPD building to prevent new spikes/clusters. Pre-treatment (PreRx) and Post-treatment (PostRx) FCV-19S values were compared using paired $t$ test. $p<.05$ was considered statistically significant. Pearson's correlation was done between FCV-19S and clinical values to study any possible relations.

\section{Results and Discussion}

Demographic details are denoted in Table 4. Out of 250(n), 177 were males and 73 were females. Age range, mean age and gender ratio were noted-showed male preponderance (Table 4). Patients' symptomatology at initial presentation to emergency department were throat pain $(150,60 \%)$, drycough $(42,16.8 \%)$, fever $(22,8.8 \%)$, loss of smell and taste $(15,6 \%)$, abdominal pain $(7,2.8 \%)$, diarrhea and breathlessness $(5,2 \%$ each), headache $(2, .8 \%)$ and nasal block $(2, .8 \%)$. Rhinorrhea and sneezing were not documented in 
Table 4 Study demographics

\begin{tabular}{|c|c|c|c|}
\hline Sr. no. & Parameter & & Value \\
\hline 1 & Age range (years) & & $15-75$ \\
\hline 2 & Mean age (years) & & $41.13 \pm 9.93$ \\
\hline 3 & Sex ratio (M:F) & & $2.4: 1$ \\
\hline \multirow[t]{3}{*}{4} & \multirow[t]{3}{*}{ Education } & High-school & $105(42 \%)$ \\
\hline & & Graduate studies & $134(53.6 \%)$ \\
\hline & & Post-graduate studies & $11(4.4 \%)$ \\
\hline \multirow[t]{3}{*}{5} & \multirow[t]{3}{*}{ Marital status } & Married & $187(74.8 \%)$ \\
\hline & & Single & $61(24.4 \%)$ \\
\hline & & Widow(er) & $2(.8 \%)$ \\
\hline \multirow[t]{3}{*}{6} & \multirow[t]{3}{*}{ Employment during lockdown } & Employed & $138(55.2 \%)$ \\
\hline & & Employed—work from home & $10(4 \%)$ \\
\hline & & Un-employed & $102(40.8 \%)$ \\
\hline \multirow[t]{4}{*}{7} & \multirow[t]{4}{*}{ Risk category } & A-No breathlessness & $237(94.8 \%)$ \\
\hline & & B1-Breathless with $>95 \% \mathrm{SPO}_{2}$ without $\mathrm{O}_{2}$ & $6(2.4 \%)$ \\
\hline & & B2-Breathless with $>95 \% \mathrm{SPO}_{2}$ with $\mathrm{O}_{2}$ & $2(.8 \%)$ \\
\hline & & $\mathrm{C}-$ Breathless with $<95 \% \mathrm{SPO}_{2}$ with $\mathrm{O}_{2}$ & $5(2 \%)$ \\
\hline \multirow[t]{2}{*}{8} & \multirow[t]{2}{*}{ Morbidity profile } & Co-morbidity & $144(57.6 \%)$ \\
\hline & & No co-morbidity & $106(42.4 \%)$ \\
\hline 9 & Smoking & Current & $93(37.2 \%)$ \\
\hline \multirow[t]{2}{*}{10} & \multirow[t]{2}{*}{ Family member with covid-19 } & No & $213(85.2 \%)$ \\
\hline & & Yes & $37(14.8 \%)$ \\
\hline
\end{tabular}

our study population. Co-morbidities included Diabetes mellitus Type-2 (38, 15.2\%), Systemic hypertension (25, $10 \%)$, coronary artery disease $(11,4.4 \%)$, hypothyroidism and bronchial asthma $(3,1.2 \%$ each).

This study probably is the first in its way to express quality-of-life changes in patients who underwent treatment for Covid-19 from an otorhinolaryngology perspective. Several incidences of discrimination and increased volume of patients attending post Covid-19 treatment counseling sessions spear-headed our study.

Study sample size was 250(n). As our center featured in The Government's Covid-19 panel of hospitals, 250 beds were allocated for dedicated Covid-19 + ve patients management. All beds were included in the study. This did not include patients below 15 years of age. Other studies sample size ranged from 5423(n) [16] and 717(n) [15] which were multicenter studies to 206(n) [17] which involved 103 Covid-19 patients matched with controls. Another study involved only adolescent population with sample size of 46 [18].

Mean age in our study was $41.13 \pm 9.93$ years with age range of 15-75. Cases peaked in the age group of 35-45 years (Table 4). Nguyen et al. [16] derived a mean age of $22 \pm 2$ in a study population comprising only medical students. Our study's gender ratio was 1:2.4 with male preponderance. Other studies [15, 18] showed male preponderance while a study by Satici et al. [19] mainly evaluating adaptation of FCV-19S in Turkish population showed female preponderance.

Educational status of our study population was categorized as High-school/Graduate studies/Post-graduate studies. This status had an impact on the thought process of the patients and understanding of the disease. This also helped alleviate the fear on Covid-19. The higher the educational status, the better was the implementation of preventive measures and better compliance to the treatment. Furthermore, this class required less supervision to follow daily medication regimen. However, in a comparable study by Tzur Bitan, et al.[20] most of the population were graduates which was in contrast to our study in which highschool level was the most recorded.

Most of the patients were married and some had other family members also admitted for Covid-19 treatment. The marital status was a factor which concerned Covid-19 affected individuals as they were also worried about other's prognosis and more depressed. In a similar study [20], marital status was recorded under 4 categories as single/married/living with partner/others. This classification however was not compatible with our study group.

Covid-19 affected individuals who were in the Information Technology (IT) sector/self-employed/well-versed with use of social media/women/work-from-home 
compatible jobs were less worried about employment scenario as compared to offline/manual workers or those who were in the lay-off category. These observations were obtained as feedback from the institute's psychiatry department. Studies like [21, 22] voiced the same concern.

Risk category into A, B and C was devised by the hospital to assess patients at initial presentation. Each category was scored by the research team as mentioned earlier. This helped indirectly to predict the clinical and mental status with current Covid-19 infection. Other studies [23, 24] did not reveal any such categorization or clinical scoring.

Morbidity profile in our study was recorded (Table 1, Fig. 1). A total of 144 (57.6\%) had pre-existing diseases and clinically fared lesser than those who were without any co-morbidities $(106,42.4 \%)$. This risk-group was given extra care as anticipation of complication was high. Other studies [16, 17, 25] also documented both systemic and psychiatric co-morbidities which accounted to $22.3 \%$ of total sample. This was almost half of comorbidity volume noted in our study.

Clinical presentation was as per Fig. 2. Most common symptom was throat pain $(60 \%, 150)$ followed by cough $(16.8 \%, 42)$ and fever $(8.8 \%, 22)$. None of the candidates complained of any sneezing/rhinitis features as primary cause for admission. Those patients who had non-respiratory symptoms did not worsen to Category B/C. Study by Wang et al. [9, 12, 26, 27] showed varied clinical presentations.

FCV-19S was the quality-of-life (QOL) assessment tool used in our study. It had been widely used either as the only tool or in comparison with other Covid-19 QOL tools. Pakpour et al. study [24] have also used other QOL tools like Fear of Covid-19 Questionnaire (FCQ) [19] and COVID Stress Scales (CSS) [28] along with FCV-19S.

FCV-19S was valued twice by the patients (Tables 5, 6). The pre-treatment and post-treatment scores were compared for any statistical significance. The mean of the total 7 -item score showed $p<.001$ which was statistically significant suggesting that the Covid-19 survivors had a definite improvement in their QOL. The individual item score was also tested and all had $p<.001$. The items $1-4$ and 7

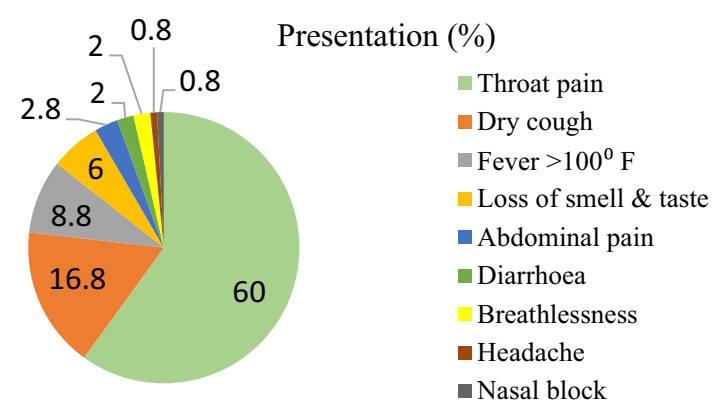

Fig. 2 Clinical presentation

had a mean positive score whereas items 5 and 6 had a mean negative score. These 2 unexpected observations indicated that some Covid-19 survivors still had mental stress even after full recovery which was contrary to common belief. On probing, discrimination in their neighborhood and restricted access to daily essentials surfaced as the cause. This highlighted that awareness was not adequate among the general population. After suggestions to the hospital infection control committee, efforts in the form of audio-visual aids on Covid-19 infection, its dangers and indiscriminate misconceptions were relayed within hospital premises and surrounding areas. This would hopefully alleviate social misconceptions and help with recovery of Covid-19 survivors. Studies on social discrimination following Covid-19 infection [29-31] have definitely been documented but the extent of scarring that the survivors have undergone may not reflect immediately on the society. In our study population, the main grievances were denying access to daily essentials or medications/ boycotting in neighborhood/physical and mental abuses (increased incidence of domestic violence/slap-injuries) as reported by the zonal policing authorities. Best remediation to prevent this misevent to go into an incubation period is to spread awareness and build armamentarium against the disease and not the survivors [32].

Pearson's correlation was analyzed between clinical category score (CCS) and FCV-19S values (Fig. 3). It was found to have a moderate negative correlation co-efficient $(-.39)$ which expressed an inverse relation between the two. Future Correlation analysis of such elements may be

Fig. 1 Co-morbidity profile

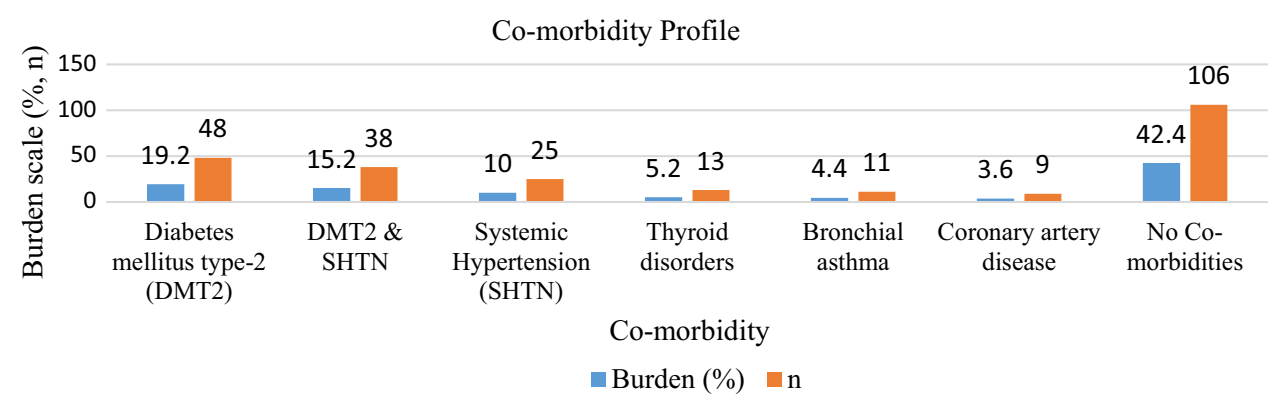


Table 5 Paired $t$ test mean values

\begin{tabular}{llcc}
\hline Parameter & & Mean & SD \\
\hline Pair 1 & PreRx_FCV-19S_Item1 & 4.7080 & .59342 \\
& PostRx_FCV-19S_Item1 & 1.3640 & .89145 \\
Pair 2 & PreRx_FCV-19S_Item2 & 4.6000 & .74446 \\
& PostRx_FCV-19S_Item2 & 2.1720 & .78029 \\
Pair 3 & PreRx_FCV-19S_Item3 & 4.0320 & .45586 \\
& PostRx_FCV-19S_Item3 & 1.3640 & .86400 \\
Pair 4 & PreRx_FCV-19S_Item4 & 4.8400 & .42794 \\
& PostRx_FCV-19S_Item4 & 1.3480 & .92429 \\
Pair 5 & PreRx_FCV-19S_Item5 & 3.9800 & .45213 \\
& PostRx_FCV-19S_Item5 & 4.9680 & .17635 \\
Pair 6 & PreRx_FCV-19S_Item6 & 3.9320 & .42908 \\
& PostRx_FCV-19S_Item6 & 4.1200 & .047935 \\
Pair 7 & PreRx_FCV-19S_Item7 & 3.6920 & .32561 \\
& PostRx_FCV-19S_Item7 & 2.1280 & .02883 \\
Pair 8 & TotalPreRx_FCV-19S_All-items & 29.7840 & .05464 \\
& TotalPostRx_FCV-19S_All-items & 17.4640 & .02707 \\
\hline
\end{tabular}

Table 6 Paired $t$ test mean differences

\begin{tabular}{|c|c|c|c|c|c|c|c|c|c|}
\hline \multicolumn{2}{|c|}{ Parameter } & \multicolumn{5}{|c|}{ Paired sample tests—paired differences } & \multirow[t]{3}{*}{$t$} & \multirow[t]{3}{*}{ df } & \multirow{3}{*}{$\begin{array}{l}\text { Sig. (2- } \\
\text { tailed) }\end{array}$} \\
\hline & & \multirow[t]{2}{*}{$\begin{array}{l}\text { Mean } \\
\text { differences }\end{array}$} & \multirow[t]{2}{*}{ SD } & \multirow[t]{2}{*}{$\begin{array}{l}\mathrm{SE} \\
\text { mean }\end{array}$} & \multicolumn{2}{|c|}{$\begin{array}{l}95 \% \text { confidence } \\
\text { interval of the } \\
\text { difference }\end{array}$} & & & \\
\hline & & & & & Lower & Upper & & & \\
\hline Pair 1 & PreRx-PostRx FCV-19S_Item1 & 3.34400 & 1.03826 & .06567 & 3.21467 & 3.47333 & 50.925 & & .000 \\
\hline Pair 2 & PreRx-PostRx FCV-19S_Item2 & 2.42800 & 1.02421 & .06478 & 2.30042 & 2.55558 & 37.482 & & .000 \\
\hline Pair 3 & PreRx-PostRx FCV-19S_Item3 & 2.66800 & .93878 & .05937 & 2.55106 & 2.78494 & 44.936 & & .000 \\
\hline Pair 4 & PreRx-PostRx FCV-19S_Item4 & 3.49200 & .98683 & .06241 & 3.36908 & 3.61492 & 55.950 & 249 & .000 \\
\hline $\begin{array}{c}\text { Pair } \\
5\end{array}$ & PreRx-PostRx FCV-19S_Item5 & -.98800 & .48662 & .03078 & -1.04862 & -.92738 & -32.102 & & .000 \\
\hline $\begin{array}{c}\text { Pair } \\
6\end{array}$ & PreRx-PostRx FCV-19S_Item6 & -.18800 & .48331 & .03057 & -.24820 & -.12780 & -6.150 & & .000 \\
\hline Pair 7 & PreRx-PostRx FCV-19S_Item7 & 1.56400 & .80029 & .05061 & 1.46431 & 1.66369 & 30.900 & & .000 \\
\hline Pair 8 & $\begin{array}{l}\text { TotalPreRx_FCV-19S-TotalPostRx_FCV- } \\
\text { 19S }\end{array}$ & 12.32000 & 3.64950 & .23081 & 11.86540 & 12.77460 & 53.376 & & .000 \\
\hline
\end{tabular}

Test values of Item Pair 5 and 6 in the FCV-19S scale have been highlighted as the mean differences between Pre- and Post-Treatment were negative. Though the $p$ value was statistically significant $(p<0.001)$, the end-point was that in Items ' 5 ' and ' 6 ', quality-of-life status was poorer than the initial record

researched and probably new data can add-on to existing literature. The purpose of correlating CCS with FCV-19S was put forth as an effort to objectively assess fear/anxiety of Covid-19 affected individuals. The higher the CCS, poorer was the FCV-19S. The benefit to the patient's mental status with improving CCS was thought-provoking. Though fear/anxiety factors are always misjudged objectively, these clinical readings laid a basic foundation to reflect the patient's mindset. Studies [19, 33, 34] had done correlation studies but with different perspectives like psychometrics, intolerance of uncertainty and predictors of Covid-19 fear respectively.

237 patients who were clinically improving were discharged. No tracheostomy was done during the period of study, as all patients were either extubated or was on ventilator (less than 10 days) or declared dead during the 


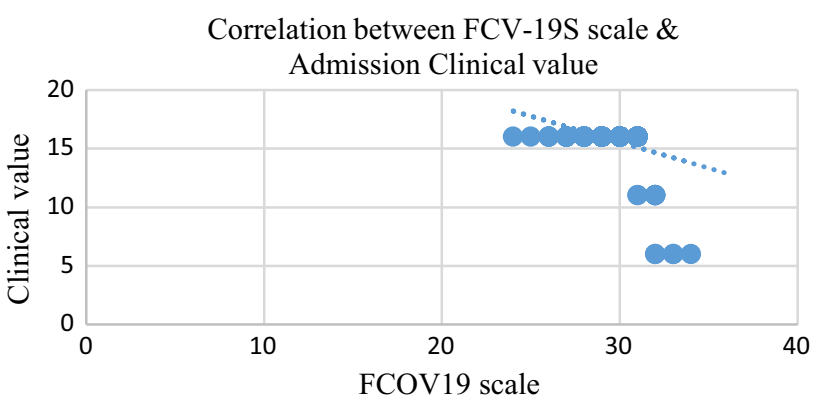

Fig. 3 Correlation graph between FCV-19S amd admission clinical value

study period. Totally, 13 patients worsened and were shifted to RICU. Complication rate was 5.2\%. Overall mortality rate $.8 \%(2 \mathrm{n})$ and ICU mortality rate $10 \%(2 \mathrm{n})$. Recovery rate was $96 \%(242 \mathrm{n})$ - 8n were still under treatment and discharge rate was $94.8 \%(237 n)$. These rates were hospital-based and may not reflect that in the community. Higher mortality rates in countries like the United States of America, Brazil may have an underlying genetic/social basis which needs further ground-breaking research. This was discussed at a institutional professional level since, India being the 2nd most populous country next to China, both countries could achieve better mortality rates [3].

\section{Limitations}

A larger sample size study could highlight grey zones in management or help refine protocols. Pediatric data not included. Benefit of $\mathrm{HCQ} /$ data on its use could not be verified. Alternative medicines and its properties were beyond the scope of this article and were not assessed. Covid-19 testing not done in new-born-vertical transmission could not be ascertained. Influence of smoking/ Body Mass Index (BMI) was not separately studied. Individual co-morbidities and their effects were not studied.

\section{Conclusion}

Unprecedented Covid-19 pandemic has been a medical/ logistical nightmare and has taken a significant toll across all sectors globally. Implementation of Social-distancing/face Masks/Sanitization (SMS) has been the backbone in achieving good control rates. Awareness on Covid-19 and prevention of spread of misinformation are the keystones in preventing discrimination of Covid-19 survivors. FCV-19S QOL tool has been a useful tool to assess mental health of the Covid-19 patients. Societal Health literacy uplift definitely comes hand-in-hand with Covid-19 management. Recent evidence of Covid-19 mutational sequence has been released by WHO as "D614G" which makes the virus more transmissible as per situation report 185. Further research input into this zone and methods to counter it would go a long way in helping the community fight Covid-19 pandemic and indirectly improve QOL.

Funding No external funding.

Availability of Data and Material Data recorded in MS Excel and analyzed

\section{Compliance with Ethical Standards}

Conflicts of interest The authors declare that they have no conflict of interest.

Ethics Approval Institutional Ethical Committee approval obtained.

Consent to Participate Written Informed consent obtained from the participants.

Consent for Publication Consented.

Code Availability MS Excel.

\section{References}

1. Naming the coronavirus disease (COVID-19) and the virus that causes it [Internet]. Who.int. 2020 [cited 10 July 2020]. https://www.who.int/emergencies/diseases/novel-coronavirus2019/technical-guidance/naming-the-coronavirus-disease-(covid2019)-and-the-virus-that-causes-it. Accessed 10 July 2020

2. WHO Coronavirus Disease (COVID-19) Dashboard [Internet]. Covid19.who.int. 2020 [cited 17 July 2020]. https:// covid19. who.int/?gclid=Cj0KCQjw3s_4BRDPARIsAJsyoLNhzR3v KusagdkNxqQjMZ5Fiw62icA6sSDHnq8UdCAEEoDG3Livga AuTBEALw_wcB. Accessed 10 July 2020

3. Who.int. 2020 [cited 27 July 2020]. https://www.who.int/docs/ default-source/coronaviruse/situation-reports/20200723-covid-19sitrep-185.pdf?sfvrsn=9395b7bf_2. Accessed 12 July 2020

4. Aggarwal S, Garcia-Telles N, Aggarwal G, Lavie C, Lippi G, Henry BM (2020) Clinical features, laboratory characteristics, and outcomes of patients hospitalized with coronavirus disease 2019 (COVID-19): early report from the United States. Diagnosis. 7(2):91-96

5. Bloch EM, Shoham S, Casadevall A et al (2020) Deployment of convalescent plasma for the prevention and treatment of COVID19. J Clin Invest. 130(6):2757-2765. https://doi.org/10.1172/ JCI138745

6. Dong L, Hu S, Gao J (2020) Discovering drugs to treat coronavirus disease 2019 D. Tzur Bitan, et al. Psychiatry Research 289 (2020) 1131004 (COVID-19). Drug. Discov. Ther. 14:58-60. https://doi.org/10.5582/ddt.2020.01012

7. Modes of transmission of virus causing COVID-19: implications for IPC precaution recommendations: scientific brief, 29 March 2020 [Internet]. Apps.who.int. 2020 [cited 17 July 2020]. https://apps.who.int/iris/handle/10665/331616. Accessed 17 July 2020

8. Guo Z, Wang Z, Zhang S, Li X, Li L, Li C et al (2020) Aerosol and surface distribution of severe acute respiratory syndrome coronavirus 2 in hospital wards, Wuhan, China, 2020. Emerg 
Infect Dis 26(7):1583-1591. https://doi.org/10.3201/eid2607. 200885

9. Wang D, Hu B, Hu C et al (2020) Clinical Characteristics of 138 hospitalized patients with 2019 novel coronavirus-infected pneumonia in Wuhan, China. JAMA 323(11):1061-1069. https:// doi.org/10.1001/jama.2020.1585

10. Ho CS, Chee CY, Ho RC (2020) Mental health strategies to combat the psychological impact of COVID-19 beyond paranoia and panic. Ann Acad Med Singapore 49:1-3

11. Qiu JY, Zhou DS, Liu J, Yuan TF (2020) Mental wellness system for COVID-19. Brain Behav Immun Brain Behav Immun 87:51-52. https://doi.org/10.1016/j.bbi.2020.04.032

12. Wang C, Pan R, Wan X, Tan Y, Xu L, Ho C et al (2020) Immediate psychological responses and associated factors during the initial stage of the 2019 coronavirus disease (COVID-19) epidemic among the general population in China. Int $\mathrm{J}$ Environ Res Public Health 17(5):1729

13. \#IndiaFightsCorona COVID-19 [Internet]. MyGov.in. 2020 [cited 21 July 2020]. https://www.mygov.in/covid-19. Accessed 17 July 2020

14. Delhi I. Indian Council of Medical Research, New Delhi [Internet]. Icmr.gov.in. 2020 [cited 27 July 2020]. https://www.icmr. gov.in/

15. Ahorsu DK, Lin C, Imani V et al (2020) The Fear of COVID-19 scale: development and initial validation. Int $\mathrm{J}$ Ment Health Addict. https://doi.org/10.1007/s11469-020-00270-8

16. Nguyen HT, Do BN, Pham KM, Kim GB, Dam HTB, Nguyen TT et al (2020) Fear of COVID-19 scale-associations of its scores with health literacy and health-related behaviors among medical students. Int J Environ Res Public Health 17(11):4164. https://doi.org/10.3390/ijerph17114164

17. Qian $G$ et al (2020) Immediate psychological distress in quarantined patients with COVID-19 and its association with peripheral inflammation: A mixed-method study. Brain Behav Immun 10:15-20. https://doi.org/10.1016/j.bbi.2020.05.038

18. Liao J, Fan S, Chen J, Wu J, Xu S, Guo Y, Li C, Zhang X, Wu C, Mou H, Song C (2020) Epidemiological and clinical characteristics of COVID-19 in adolescents and young adults. The Innovation 1(1): 100001

19. Satici B, Gocet-Tekin E, Deniz ME et al (2020) Adaptation of the fear of COVID-19 scale: its association with psychological distress and life satisfaction in Turkey. Int $\mathrm{J}$ Ment Health Addict. https://doi.org/10.1007/s11469-020-00294-0

20. Tzur Bitan D, Grossman-Giron A, Bloch Y, Mayer Y, Shiffman N, Mendlovic S (2020) Fear of COVID-19 scale: psychometric characteristics, reliability and validity in the Israeli population. Psychiatry Res 289:113100. https://doi.org/10.1016/j.psychres. 2020.113100

21. Evans J, Repper J (2000) Employment, social inclusion and mental health. J Psychiatr Ment Health Nurs 7:15-24

22. Modini M, Joyce S, Mykletun A, Christensen H, Bryant RA, Mitchell PB, Harvey SB (2016) The mental health benefits of employment: results of a systematic metareview. Aust. Psychiatry 24:331-336

23. Liu CH, Emily Z, Ga TFW, Sunah H, Hyeouk "Chris" H (2020) Factors associated with depression, anxiety, and PTSD symptomatology during the COVID-19 pandemic: clinical implications for U.S. young adult mental health Psychiatry Research 290, Article 113172

24. Pakpour AH, Griffiths MD, Lin C (2020) Assessing psychological response to the COVID-19: the fear of COVID-19 scale and the COVID stress scales. Int $J$ Ment Health Addict. https://doi.org/10.1007/s11469-020-00334-9

25. Lorant V, Deliège D, Eaton W, Robert A, Philippot P, Ansseau M (2003) Socioeconomic inequalities in depression: a meta-analysis. Am J Epidemiol 157:98-112. https://doi.org/10.1093/ aje/kwf 182

26. Wang Cuiyan, Pan Riyu, Wan Xiaoyang, Tan Yilin, Xu Linkang, McIntyre Roger S, Choo Faith N, Tran Bach, Ho Roger, Sharma Vijay K, Ho Cyrus (2020) A longitudinal study on the mental health of general population during the COVID-19 epidemic in China. Brain Behav Immun 10:15-20. https://doi.org/10.1016/ j.bbi.2020.04.028

27. Huang C, Wang Y, Li X, Ren L, Zhao J, Hu Y, Cheng Z et al (2020) Clinical features of patients infected with 2019 novel coronavirus in Wuhan, China. The Lancet 395(10223):497-506. https://doi.org/10.1016/S0140-6736(20)30183-5

28. Taylor S, Landry C, Paluszek M, Fergus TA, McKay D, Asmundson GJ (2020) Development and initial validation of the COVID stress scales. J Anxiety Disord 72:102232. https:// doi.org/10.1016/j.janxdis.2020.102232

29. Tan W, Hao F, McIntyre RS, Jiang L, Jiang X, Zhang L et al (2020) Is returning to work during the COVID-19 pandemic stressful? A study on immediate mental health status and psychoneuroimmunity prevention measures of Chinese workforce. Brain Behav Immun 87:84-92. https://doi.org/10.1016/j.bbi. 2020.04.055

30. Xinhua (2020) State council's tips on workplace covid-19 prevention, control [Online]. China.org.cn: Xinhua. http://www. china.org.cn/china/2020-03/05/content_75776272.htm. Accessed 17 July 2020

31. Pappas G, Kiriaze IJ, Giannakis P, Falagas ME (2009) Psychosocial consequences of infectious diseases. Clin Microbiol Infect 15(8):743-747. https://doi.org/10.1111/j.1469-0691. 2009.02947.x

32. Pfefferbaum B, North CS (2020) Mental health and the Covid-19 pandemic. N Engl J Med 383(6):510-512. https://doi.org/ 10.1056/NEJMp2008017

33. Bakioğlu F, Korkmaz O, Ercan H (2020) Fear of COVID-19 and positivity: mediating role of intolerance of uncertainty, depression, anxiety, and stress. Int J Mental Health Addict. https:// doi.org/10.1007/s11469-020-00331-y

34. Mertens G, Gerritsen L, Duijndam S, Salemink E, Engelhard IM (2020) Fear of the coronavirus (COVID-19): predictors in an online study conducted in March 2020. J Anxiety Disord 74:102258. https://doi.org/10.1016/j.janxdis.2020.102258

Publisher's Note Springer Nature remains neutral with regard to jurisdictional claims in published maps and institutional affiliations. 